\title{
ARTICLES
}

\section{Trends in Cancer Mortality in 15 Industrialized Countries, 1969-1986}

\author{
David G. Hoel,* Devra L. Davis, Anthony B. Miller, Edward J. \\ Sondik, Anthony J. Swerdlow
}

Background: Assessing trends in cancer provides a means for gauging progress against the disease, estimating future demands for care and treatment, and suggesting clues about shifting causal factors that may account for the more recent changes. Purpose: This study was designed to evaluate trends in the major sites of cancer associated with high mortality rates in 15 industrialized countries. To highlight differences among regions, we grouped these countries into six geographic areas: United States, Eastern Europe, Western Europe, East Asia, Oceania, and Nordic countries. In addition, cancer mortality trends in these regions were compared with incidence patterns in the United States. Methods: Data provided by the World Health Organization were used to evaluate age-specific mortality trends from 1969 through 1986 for lung, breast, prostate, stomach, and colorectal cancers and for all other sites considered as a group. We also assembled and analyzed data from the Surveillance, Epidemiology, and End Results (SEER) Program of the National Cancer Institute for the same sites and age groups from 1973 through 1986. Results: Over the period 1969 through 1986, recorded cancer mortality in persons aged 45 years and older in the six regions studied has increased for lung, breast, and prostate cancers in most age groups, while the decline in stomach cancer mortality is substantial. The increase in lung cancer deaths in men aged 45-54 years has slowed greatly or reversed in all areas except Eastern Europe and East Asia. Trends for intestinal cancer vary by age and region. For all other sites considered as a group, increases have occurred for persons older than 64 years in most regions. In Eastern Europe, there are disturbingly high rates and rapid increases for several of the major forms of cancer in persons aged $\mathbf{4 5 - 5 4}$ years. In general, trends for cancer incidence in the United States parallel those for mortality. For intestinal cancer, however, incidence has increased while mortality has declined. Conclusions: The trends we report cannot be explained solely by changes in cigarette smoking or aging. Other causes of changes in cancer incidence and mortality need to be determined. Implications: The increasing and decreasing trends in mortality from and incidence of cancer that we found are important for health care planning and may also suggest opportunities for research in cancer prevention. [ $J$ Natl Cancer Inst 84:313-320, 1992]

Differences in patterns of disease between and within countries can provide important clues about changing causal factors. Where changes occur over a relatively short time, they can suggest hypotheses for vital research initiatives. This study examined shifts in patterns of cancer in a number of industrialized countries as recently as 1986 .

About one fifth of the 11 million deaths in the industrialized world each year are attributable to cancer $(1,2)$. We examined the mix of increases and decreases in the major cancer sites in 15 countries for specific 10-year age groups. For ages 45-84 years, age-specific rates were used to facilitate the comparison of trends among countries in the age group in which most cancer occurs. In the countries we studied, about $5 \%$ of the total number of deaths from all cancers occurred in people less than 45 years of age, while about $60 \%$ occurred in those aged 65 years and over.

We expanded on previous work that analyzed mortality and incidence trends in the United States $(3,4)$ and mortality trends in several other industrialized countries $(5-10)$ by identifying

Received July 22, 1991; revised November 21, 1991; accepted December 9, 1991.

D. G. Hoel, National Institute of Environmental Health Sciences, Research Triangle Park, N.C.

D. L. Davis, National Research Council, Washington, D.C.

A. B. Miller, Department of Preventive Medicine and Biostatistics, University of Toronto, Toronto, Ontario, Canada; and Cancer and Palliative Care Unit, World Health Organization, Geneva, Switzerland.

E. J. Sondik, Division of Cancer Prevention and Control, National Cancer Institute, Bethesda, Md.

A. J. Swerdlow, London School of Hygiene and Tropical Medicine and Office of Censuses and Population Surveys, London.

We thank the World Health Organization for providing the cancer mortality data on which this article is based.

${ }^{*}$ Correspondence to: David G. Hoel, Ph.D., National Institute of Environmental Health Sciences, P.O. Box 12233, Research Triangle Park, NC 27709. 
mortality trends from 1969 through 1986 in 15 countries for which the World Health Organization (WHO) believes there are data of good quality. To aid in the interpretation of the mortality data, we also examined trends in rates of cancer incidence in the United States for the same cancer sites as recently as 1986.

\section{Methods}

To facilitate international comparisons of cancer patterns, we grouped countries geographically as follows: United States; Western Europe (France, Federal Republic of Germany, Italy, England, and Wales); Eastern Europe (former German Democratic Republic, Czechoslovakia, and Hungary); Nordic countries (Finland and Norway); East Asia (Hong Kong, Japan, and Singapore); and Oceania (New Zealand and Australia). Such a grouping of countries can obscure individual country patterns, but it permits broad assessments of differences among geographic regions.

We have combined data for the region of East Asia from three very different locations-the countries of Japan and Singapore and the city of Hong Kong. These areas were combined because their data are more reliable than data from other countries in the region, although not necessarily representative of the entire region. We recognize that Asia includes a number of developing countries such as China and India for which reliable mortality statistics are not available for this time period.

To prevent country effects from dominating, we did not weight the individual country rates by population. Instead, we calculated an arithmetic average of age-specific rates for each country within the region, using the technique of Lopez (I). We also calculated age-adjusted rates standardized to the U.S. 1986 age distribution for ages 45-84 years.

For the period from 1969 through 1986, WHO provided annual data on cancer deaths with corresponding population data for the 15 countries. Annual age-specific mortality rates in all these groupings of countries were calculated separately for the most common cancer sites (lung, stomach, intestine, breast, and prostate) and for all other sites as a group. Mortality rates for intestinal cancer were used in these analyses to ensure comparability with national rates for colon cancer and rectal cancer. (The contribution of cancer of the small intestine is a very minor part of intestinal cancer.) There can be considerable age-related variations in the effects of cancer treatment, in incidence trends, and in reliability of data, which tends to be poorer at older ages. Because of these age-specific effects, we examined age-specific rates in 10-year intervals for subjects 45-84 years of age.

Using data from the U.S. Surveillance, Epidemiology, and End Results (SEER) Program, we derived annual age-specific incidence rates for the same cancer sites from 1973 through 1986. To calculate the average yearly rate changes, simple normal theory linear regression analysis was applied to the observed rates. Tables 1-6 report the yearly changes in each region as a percentage of the 1986 observed rate. For changes in the SEER incidence rates, we also report statistical significance in the linear regression at the $P<.01$ level. (Significance levels were not given for the regions because of the complexity of the combined country data used to produce the regional rates.)

\section{Results}

\section{Stomach Cancer Mortality}

Table 1 shows a substantial annual decline in stomach cancer mortality of about $2 \%-7 \%$ in each region and in each age group. Fig. 1 shows a similar decline for each region. In the United States, the rate of decline increased with increasing age, whereas in East Asian males, the opposite is true. Elsewhere, there is no clear age-related pattern.

Stomach cancer mortality rates are highest in East Asia, followed very closely by Eastern Europe, and are lowest in the United States. Rates are higher for males than for females in every region, and the ratio of mortality for males versus females is remarkably similar in each country and for each age group. The fact that the rates in Nordic and Westem European countries are two to three times higher than those in the United States is of particular interest (lI).

\section{Lung Cancer Mortality}

The increase in lung cancer deaths has been substantial for most age groups (Table 2), but the increase has slowed greatly or has reversed in males ages 45-54 years of age in all areas except Eastern Europe and East Asia. Both the high mortality rate and the rate of increase in Eastern European males aged 45-54 years particularly stand out. Rates for females of all ages are increasing worldwide. Among females, the greatest percentage and absolute increases in lung cancer occurred in the United States. For women aged 75-84 years, rates in East Asia are greater than those in the United States. Fig. 2 shows that the rates for males in all countries are higher than those for females, but the extent of this disparity varies greatly by region.

\section{Prostate Cancer Mortality}

Table 3 and Fig. 3 show that prostate cancer mortality is increasing in all areas and at all ages except for ages 75-84 years in Oceania. Although the absolute rates are lowest in East Asia, the rates of increase for each age group are generally highest in this region. The absolute rates at ages $65-74$ and $75-84$ years are highest in the Nordic countries, with rates of increase at these ages greater than for any region other than East Asia.

\section{Breast Cancer Mortality}

Table 3 and Fig. 4 indicate that breast cancer mortality is increasing in all regions in most age groups-excepting the youngest age group in the United States, the two youngest age groups in the Nordic countries, and the oldest age group in Oceania. Apart from the age group 75-84 years in Oceania, the rates of increase are greater for people aged 65-84 years than at younger ages. The greatest increases in breast cancer mortality at young ages were in Eastern Europe. Although breast cancer is increasing in all age groups, East Asian females continue to have substantially lower rates than females in other regions.

\section{Intestinal Cancer Mortality}

The intestinal cancer rates shown in Table 4 and Fig. 5 primarily represent colorectal cancers because of the low rates of cancers of the small intestine. Intestinal cancer mortality is greatest in Oceania and Eastern Europe in both males and fe- 
Table 1. Mortality rates per 100000 population for stomach cancer in 1986 and percent annual change from 1969 through $1986^{*}$

\begin{tabular}{|c|c|c|c|c|c|c|}
\hline \multirow[b]{2}{*}{ Age group, $y$} & \multicolumn{6}{|c|}{ Montality rate (\% annual change) } \\
\hline & United States & Westem Europe & Eastern Europe & Nordic countries & East Asia & Oceania \\
\hline \multicolumn{7}{|c|}{ Males } \\
\hline $45-54$ & $6(-2.3)$ & $13(-4.6)$ & $20(-4.1)$ & $12(-6.1)$ & $23(-6.1)$ & $8(-2.7)$ \\
\hline $55-64$ & $17(-3.2)$ & $42(-5.8)$ & $63(-5.9)$ & $36(-6.2)$ & $73(-5.6)$ & $29(-3.0)$ \\
\hline $65-74$ & $36(-3.6)$ & $112(-4.4)$ & $157(-5.4)$ & $92(-6.7)$ & $183(-3.5)$ & $65(-4.1)$ \\
\hline $75-84$ & $64(-4.0)$ & $221(-3.4)$ & $271(-4.5)$ & $215(-4.8)$ & $291(-1.0)$ & $136(-3.9)$ \\
\hline Total† & $22(-3.5)$ & $67(-4.4)$ & $92(-5.1)$ & $59(-5.9)$ & $104(-3.4)$ & $41(-3.7)$ \\
\hline \multicolumn{7}{|c|}{ Females } \\
\hline $45-54$ & $2(-3.5)$ & $5(-4.0)$ & $9(-4.5)$ & $7(-6.1)$ & $13(-4.9)$ & $5(-1.6)$ \\
\hline $55-64$ & $7(-3.6)$ & $16(-6.1)$ & $23(-7.1)$ & $16(-5.3)$ & $28(-5.9)$ & $8(-6.5)$ \\
\hline $65-74$ & $14(-4.6)$ & $45(-6.1)$ & $70(-6.8)$ & $42(-6.6)$ & $65(-5.5)$ & $24(-5.7)$ \\
\hline $75-84$ & $31(-4.8)$ & $112(-5.4)$ & $143(-6.2)$ & $105(-6.6)$ & $139(-2.1)$ & $63(-5.0)$ \\
\hline Total $\dagger$ & $11(-4.4)$ & $34(-5.7)$ & $48(-6.5)$ & $33(-6.4)$ & $49(-4.1)$ & $19(-5.1)$ \\
\hline
\end{tabular}

*Percent annual change is based on the average annual change for the period 1969-1986 expressed as a percentage of the 1986 rate.

†Age-adjusted rate based on 1986 U.S. population.

males. Mortality is decreasing in all age groups in males and females for both the United States and Western Europe. The opposite is occurring in Eastern Europe and East Asia, where rates are increasing at a rate of $1 \%-2 \%$ annually, with the mortality rate in Eastern European men the highest of all regions. Rates for males are uniformly higher than for females in each age group and in each region.

\section{Mortality for Other Cancers}

Table 5 indicates that mortality attributable to cancers other than stomach, lung, prostate, breast, and intestinal cancers has increased in males over age 64 years in all regions and in younger males, except for the United States and Nordic countries. For women, cancer mortality due to cancers in these other sites has generally decreased in the younger age groups (45-64 years) and generally increased in older age groups (65-84 years). Fig. 6 indicates that the highest rates occur in Europe and

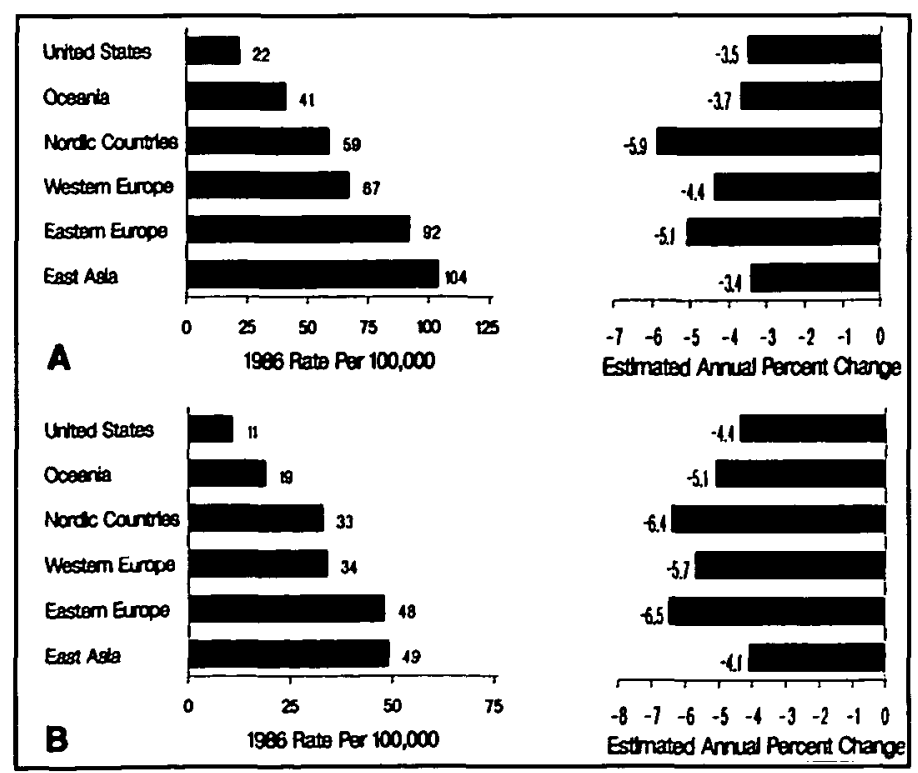

Fig. 1. Stomach cancer in males (A) aged $45-84$ years and females (B) aged 45 84 years. Mortality data provided by WHO (1969-1986). have increased in all regions for males in the age group 45-84 years.

\section{U.S. Cancer Incidence}

Annual rates of cancer incidence recorded in the U.S. SEER Program increased for several of these same major sites of cancer over the period 1973 through 1986 (Table 6). Within our broad groupings for age and type of cancer, only two groups showed a statistically significant decrease in incidence: stomach cancer and "other cancers" in females aged 45-64 years.

\section{Discussion}

Worldwide reductions in stomach cancer mortality are noteworthy and encouraging. Dietary factors and improvements in food storage and handling are thought to be major factors relevant to this decline. Reduction in toxic methods of food preservation, such as smoking and pickling, declining salt consumption, widespread use of refrigeration, and increasing fruit and vegetable consumption, may account for many of the changes in stomach cancer incidence (12).

Changes in lung cancer mortality are largely attributable to changes in smoking habits. Cigarette smoking is the single most important preventable cause of cancer, accounting for about $30 \%$ of all cancer deaths. Worldwide, cigarette smoking causes more than 3 million deaths annually (13). It is projected that in about 40 years, smoking will claim more than 10 million lives annually if current trends of increasing cigarette use continue (Peto R, Lopez A: manuscript in preparation). Cigarette smoking also contributes to cancers at a number of other sites, notably the oropharynx, larynx, bladder, esophagus, kidney, and pancreas (14). While most of the changes in lung cancer mortality are due to changes in smoking habits, they may also, to a smaller extent, reflect changes in air pollution, diet, and occupational factors (15). In East Asia, high rates of lung cancer may be related to the use of smoky, carbonaceous fuels for domestic cooking and heating (16).

The linear trend analysis we used does not reveal subtle time changes and differences among countries. For instance, regard- 
Table 2. Mortality rates per 100000 population for lung cancer in 1986 and percent annual change from 1969 through $1986 *$

\begin{tabular}{|c|c|c|c|c|c|c|}
\hline \multirow[b]{2}{*}{ Age group, $y$} & \multicolumn{5}{|c|}{ Mortality rate (\% annual change) } & \multirow[b]{2}{*}{ Oceania } \\
\hline & United States & Western Europe & Eastem Europe & Nordic countries & East Asia & \\
\hline \multicolumn{7}{|c|}{ Males } \\
\hline $\begin{array}{l}45-54 \\
55-64 \\
65-74 \\
75-84\end{array}$ & $\begin{array}{r}34(2.8) \\
92(3.9) \\
148(4.4) \\
142(3.8)\end{array}$ & $\begin{array}{l}10(0.6) \\
38(2.5) \\
69(2.8) \\
82(2.7)\end{array}$ & $\begin{array}{l}13(2.8) \\
31(1.6) \\
54(1.3) \\
73(0.4)\end{array}$ & $\begin{array}{ll}11 & (3.0) \\
29 & (3.5) \\
49 & (3.3) \\
56 & (2.2)\end{array}$ & $\begin{array}{r}14(0.6) \\
50(0.4) \\
141(2.1) \\
201(3.5)\end{array}$ & $\begin{array}{rr}16 & (1.8) \\
52 & (2.9) \\
95 & (3.8) \\
107 & (3.5)\end{array}$ \\
\hline Total $\dagger$ & $96(3.9)$ & $44(2.5)$ & $37(1.3)$ & $33(3.0)$ & $84(2.2)$ & $60 \quad(3.3)$ \\
\hline
\end{tabular}

*Percent annual change is based on the average annual change for the period 1969-1986 expressed as a percentage of the 1986 rate.

$\dagger$ Age-adjusted rate based on 1986 U.S. population.

ing lung cancer patterns, the net effect of combining England and Wales with Western Europe is to obscure the downturn in mortality in most age groups of males in England. Moreover, the linear regression analyses in our tables cannot reveal other recent changes, such as those that are occurring with decreases in lung cancer in males in several countries. These changes are readily apparent (Figs. 7 and 8 ) in the United States, England, and Wales (6). Also, Fig. 9 illustrates the rapidly increasing lung cancer mortality rates among U.S. women.

Prostate cancer deaths have increased in all regions, but they show important variations. The rates in East Asia are from four to six times lower than those in all the other regions but are increasing rapidly. Nordic countries have the highest overall rates. Dietary factors may be implicated, along with other environmental exposures that could account for these substantial differences.

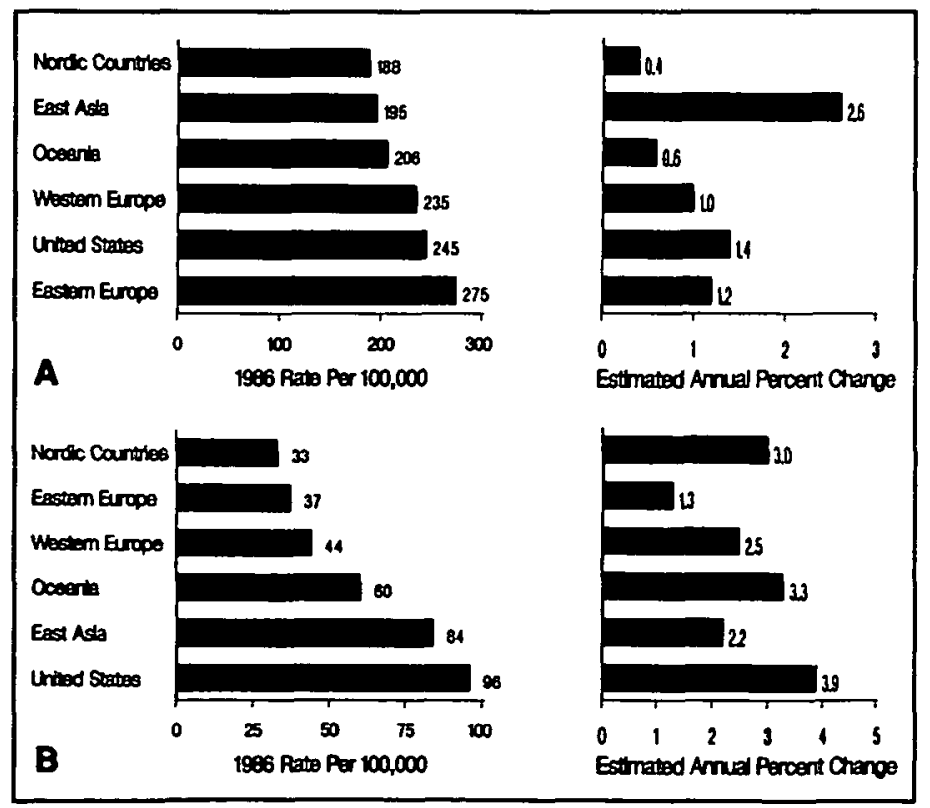

Fig. 2. Lung cancer in males (A) aged 45-84 years and females (B) aged 45-84 years. Mortality data provided by WHO (1969-1986).
In the United States, the SEER data suggest that some of the recorded increase in prostate cancer incidence may reflect improved detection and increased access to health care. Gerber and Chodak (17) correlate the increased use of transurethral resection of the prostate with the recorded increase in prostate cancer incidence. While the incidence of prostate cancer has risen considerably, mortality has increased at a much slower rate (4). It is possible that the increased use of transurethral resection of the prostate has influenced both recorded incidence and prostate cancer mortality. Additional studies are needed to resolve this matter because prostate cancer remains one of the major causes of cancer mortality in men.

Breast cancer mortality in women at older ages has been increasing in Western Europe, Eastern Europe, and East Asia $(18,19)$. This increase often has been attributed to changes in risk factors for breast cancer, such as dietary fat consumption, changes in parity distribution, and later age at birth of the first child $(20,2 I)$. However, some analyses suggest that changes in child-bearing patterns do not explain much of recent trends $(22,23)$.

Age-specific analyses of breast cancer mortality show that different trends are occurring in different regions. For example, breast cancer mortality is declining in premenopausal women in the United States (24) and in Nordic countries, but not elsewhere. The reasons for this decline are unclear, but they probably do not relate to detection of breast cancer through screening programs because screening was not generally conducted on women under the age of 50 years during the years 1973-1986 (25). Moreover, there is little evidence, at least in the first 10 years after initiation of screening (26), that screening reduces breast cancer mortality in women aged $40-49$ years.

One possible explanation for the downturn in breast cancer mortality in younger women is the use of adjuvant chemotherapy for breast cancer (27). Treatment may also shift premenopausal breast cancer deaths to the postmenopausal group, but this explanation does not account for the increases in breast cancer mortality in women over the age of 65 years. It may be that increased mortality in older women reflects exposure to unknown risk factors or promoters in the early part of this century. 
Table 3. Mortality rates per 100000 population for prostate and breast cancers in 1986 and percent annual change from 1969 through $1986^{*}$

\begin{tabular}{|c|c|c|c|c|c|c|c|}
\hline \multirow[b]{2}{*}{ Cancer } & \multirow[b]{2}{*}{ Age group, y } & \multicolumn{6}{|c|}{ Mortality rate (\% annual change) } \\
\hline & & United States & Western Europe & Eastem Europe & Nordic countries & East Asia & Oceania \\
\hline \multicolumn{8}{|c|}{ Males } \\
\hline \multirow[t]{5}{*}{ Prostate } & $45 \cdot 54$ & $3(0.4)$ & $2(0.8)$ & $2(2.1)$ & $2(4.4)$ & $1(1.4)$ & $3(0.5)$ \\
\hline & $55-64$ & $25(0.4)$ & $19(0.2)$ & $21(0.3)$ & $25 \quad(0.9)$ & $5(2.1)$ & $22(1.7)$ \\
\hline & $65-74$ & $111(0.3)$ & $102(1.0)$ & $107(1.1)$ & $132(1.2)$ & $23(1.7)$ & $116(1.0)$ \\
\hline & $75-84$ & $322(0.6)$ & $326(0.8)$ & $289(0.4)$ & $421 \quad(1.4)$ & $72(2.9)$ & $355(-0.3)$ \\
\hline & Total $\dagger$ & $68(0.5)$ & $65(0.9)$ & $63(0.7)$ & $84(1.3)$ & $15(2.3)$ & $72(0.4)$ \\
\hline \multicolumn{8}{|c|}{ Females } \\
\hline \multirow[t]{5}{*}{ Breast } & $45-54$ & $45(-1.0)$ & $50(0.5)$ & $42(0.9)$ & $37(-0.3)$ & $22(0.7)$ & $49(0.4)$ \\
\hline & $55-64$ & $81(0.2)$ & $81(0.9)$ & $68(1.1)$ & $62(-0.3)$ & $31(0.7)$ & $82(0.5)$ \\
\hline & $65-74$ & $110(0.7)$ & $107(1.2)$ & $95(1.6)$ & $85 \quad(0.9)$ & $38(1.3)$ & $102(0.7)$ \\
\hline & $75-84$ & $136(0.6)$ & $149(1.1)$ & $130(1.1)$ & $135(1.5)$ & $48(1.2)$ & $131(-0.5)$ \\
\hline & Total $\dagger$ & $85 \quad(0.3)$ & $88(1.0)$ & $76(1.2)$ & $71 \quad(0.6)$ & $33(1.0)$ & $84(0.3)$ \\
\hline
\end{tabular}

*Percent annual change is based on the average annual change for the period 1969-1986 expressed as a percentage of the 1986 rate.

$\dagger$ Age-adjusted rate based on 1986 U.S. population.

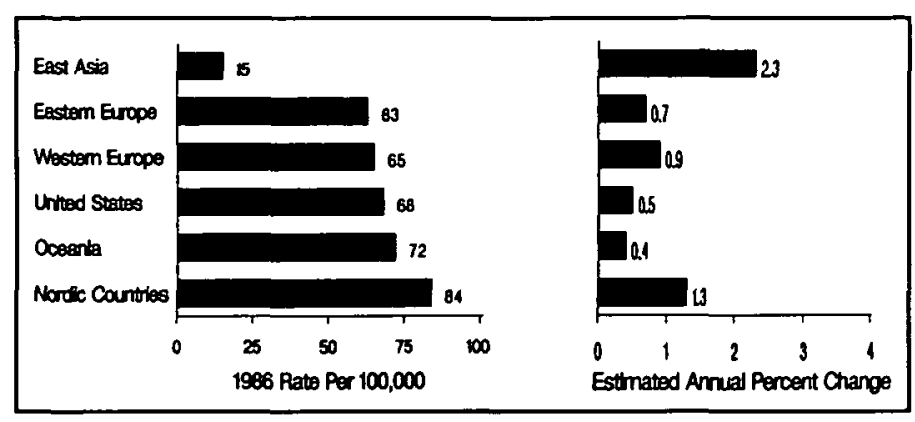

Fig. 3. Prostate cancer in males aged $45-84$ years. Mortality data provided by WHO (1969-1986).

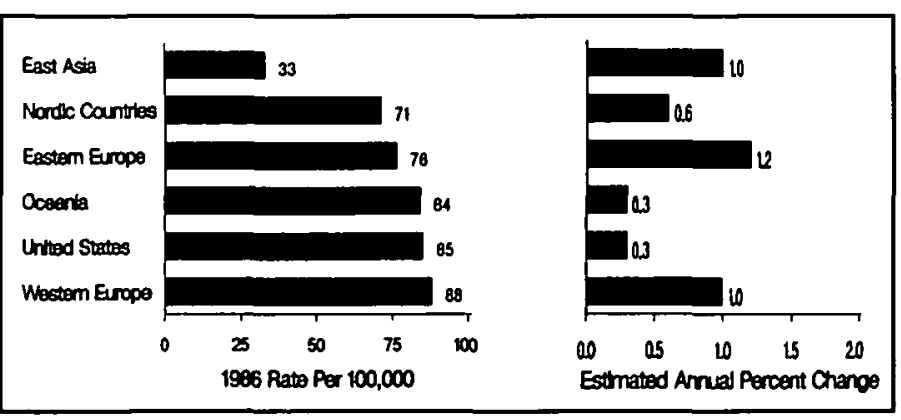

Fig. 4. Breast cancer in females aged $45-84$ years. Mortality data provided by WHO (1969-1986).

Mortality from intestinal cancer is declining at all ages and in both sexes in the United States and in Western Europe. This decline has also been noted in Canada for the last 10-15 years (20). Some of the dietary and lifestyle modifications that are believed to have contributed to the decline in cardiovascular disease mortality in North America and Western Europe might also contribute to a decline in mortality from intestinal cancer in these regions. In contrast, intestinal cancer mortality is increasing in Eastern Europe and in East Asia.

In general, trends for cancer incidence in the United States parallel those for mortality. However, in the United States, intestinal cancer incidence has increased while mortality has declined. Cancer registries in the United States show an increasing incidence of specific types of cancer in men and women aged
45-84 years (4). More complete registration or, possibly, inclusion of more borderline cases and improved treatment may account for the differences in mortality rates.

The "other cancer" category in Table 5 includes several cancer sites but excludes most smoking-related cancers. For men and women over age 64 years, worldwide increases are generally evident in these other forms of cancer. Site-specific analyses are needed to identify what cancer types are contributing to these trends.

\section{Conclusions}

When recorded deaths from lung cancer began to surge in the 1940 s, a number of analysts asserted that this phenomenon was due solely to improved diagnosis and detection of deaths previously attributed to tuberculosis $(28,29)$. However, within a few decades, the link of lung cancer with cigarette smoking was firmly established. While diagnostic factors obviously have a role in reported increases in incidence, the assumption should not be made that they completely account for the broad international trends in mortality that we have described.

In East Asia and Eastern Europe, the nature of the trends must be carefully appraised. In these regions, access to care, the quality of medical diagnosis, and the use of medical technology may have recently shifted. Thus, it is distinctly possible that relatively low mortality rates in these regions at the beginning of our study time were due to under-ascertainment of the true rate. Consequently, the relatively large increases in rates in East Asia and Eastern Europe should be cautiously interpreted.

Nonetheless, the fact that similar trends are occurring for several major sites of cancer throughout these regions is noteworthy. The explanation for changes in cancer mortality in developed countries in older age groups involves factors and exposures that may have occurred many years ago $(30,3 I)$.

Changes in mortality rates for lung cancer and for some of the sites included in the grouping "other cancer" largely reflect changes in cigarette smoking patterns. However, we have identified changes in the incidence and mortality rates for cancers at other sites in the middle and older age groups throughout the 


\begin{tabular}{|c|c|c|c|c|c|c|}
\hline \multirow[b]{2}{*}{ Age group, y } & \multicolumn{5}{|c|}{ Mortality rate (\% annual change) } & \multirow[b]{2}{*}{ Oceania } \\
\hline & United States & Westem Europe & Eastem Europe & Nordic countries & East Asia & \\
\hline & & & Males & & & \\
\hline $45-54$ & $16(-0.8)$ & $15(-0.3)$ & $25(1.9)$ & $14(0.1)$ & $17(2.1)$ & $28(1.2)$ \\
\hline $55-64$ & $52(-0.5)$ & $51(-0.6)$ & $77(1.3)$ & $43(1.1)$ & $40(1.5)$ & $80(1.4)$ \\
\hline $65-74$ & $123(-0.4)$ & $125(-0.6)$ & $183(1.8)$ & $115(1.4)$ & $112(1.8)$ & $144(0.4)$ \\
\hline $75-84$ & $232(-0.3)$ & $263(-0.1)$ & $316(1.8)$ & $224(1.1)$ & $181(1.5)$ & $283(0.2)$ \\
\hline \multirow[t]{2}{*}{ Totalł } & $75(-0.4)$ & $78(-0.4)$ & $109(1.7)$ & $69(1.2)$ & $64(1.7)$ & $98(0.7)$ \\
\hline & & & Females & & & \\
\hline $45-54$ & $13(-2.3)$ & $12(-1.7)$ & $17(1.2)$ & $13(0.0)$ & $14(1.2)$ & $22(0.5)$ \\
\hline $55-64$ & $36(-1.7)$ & $35(-1.4)$ & $47(0.7)$ & $33(1.1)$ & $34(2.1)$ & $67(0.4)$ \\
\hline $65-74$ & $82(-1.5)$ & $80(-1.0)$ & $115(1.5)$ & $81(0.7)$ & $69(2.3)$ & $114(-0.2)$ \\
\hline $75-84$ & $158(-1.1)$ & $170(-1.2)$ & $212(1.3)$ & $163(0.0)$ & $136(2.9)$ & $223(-0.8)$ \\
\hline Totalł & $58(-1.4)$ & $59(-1.2)$ & $79(1.2)$ & $58(0.4)$ & $51(2.4)$ & $88(-0.2)$ \\
\hline
\end{tabular}

*Small intestine, colon, and rectum.

$\dagger$ Percent annual change is based on the average annual change for the period 1969-1986 expressed as a percentage of the 1986 rate.

$\ddagger$ Age-adjusted rate based on 1986 U.S. population.

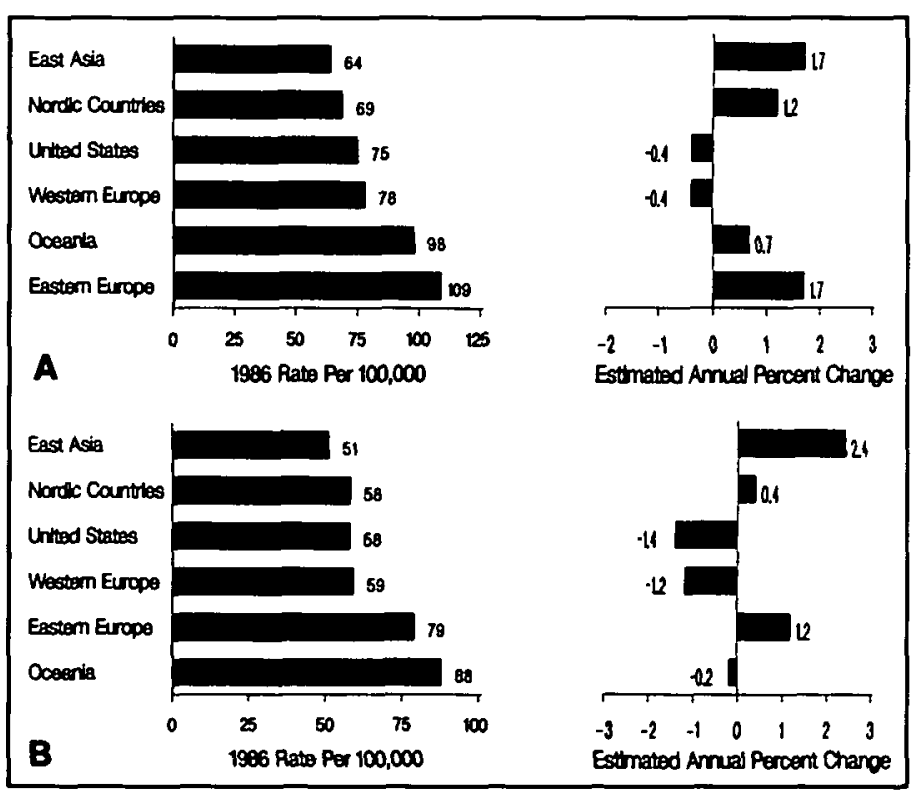

Fig. 5. Intestinal cancer in males (A) aged 45-84 years and females (B) aged 4584 years. Mortality data provided by WHO $(1969-1986)$.

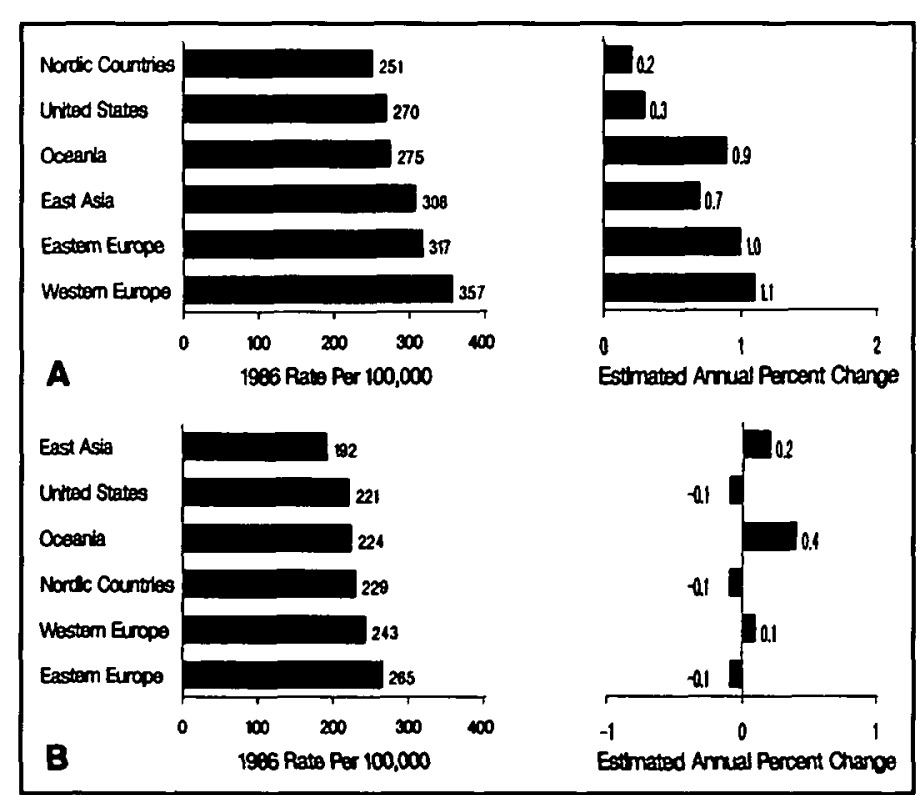

Fig. 6. Other cancers in males (A) aged 45-84 years and females (B) aged 45-84 years. Monality data provided by WHO (1969-1986).

Table 5. Mortality rates per 100000 from other cancers* in 1986 and percent annual change from 1969 through $1986 \dagger$

\begin{tabular}{|c|c|c|c|c|c|c|}
\hline \multirow[b]{2}{*}{ Age group, $y$} & \multicolumn{6}{|c|}{ Mortality rate (\% annual change) } \\
\hline & United States & Western Europe & Eastem Europe & Nordic countries & East Asia & Oceania \\
\hline \multicolumn{7}{|c|}{ Males } \\
\hline $45-54$ & $83(-0.2)$ & $113(1.3)$ & $124 \quad(2.3)$ & $63(-1.1)$ & $115 \quad(0.2)$ & $78 \quad(0.3)$ \\
\hline $55-64$ & $217(-0.1)$ & $288 \quad(0.8)$ & $273(1.2)$ & $191(-0.3)$ & $264(0.3)$ & $204(0.7)$ \\
\hline $65-74$ & $420(0.2)$ & $554 \quad(0.9)$ & $491 \quad(0.8)$ & $393(0.3)$ & $471 \quad(0.5)$ & 459 (1.1) \\
\hline $75-84$ & $707 \quad(0.9)$ & $920(1.5)$ & $693(0.6)$ & $730 \quad(0.8)$ & 712 (1.6) & $726(1.1)$ \\
\hline Total $\neq$ & $270(0.3)$ & 357 (1.1) & $317(1.0)$ & $251 \quad(0.2)$ & $308(0.7)$ & $275(0.9)$ \\
\hline \multicolumn{7}{|c|}{ Females } \\
\hline $45-54$ & $67(-2.0)$ & $70(-2.2)$ & $89(-0.7)$ & $63(-2.1)$ & $69(-2.3)$ & $59(-1.7)$ \\
\hline $55-64$ & $162(-0.6)$ & $166(-0.6)$ & $198(-0.2)$ & $154(-0.2)$ & $140(-1.0)$ & $165(0.1)$ \\
\hline $65-74$ & $312(0.1)$ & $338 \quad(0.4)$ & $380(0.2)$ & $309(-0.3)$ & $261 \quad(0.6)$ & $311 \quad(0.7)$ \\
\hline $75-84$ & $508 \quad(0.5)$ & $598 \quad(0.8)$ & $568(-0.1)$ & $589(0.4)$ & 438 (1.4) & $540 \quad(0.7)$ \\
\hline Totalł & $221(-0.1)$ & $243(0.1)$ & $265(-0.1)$ & $229(-0.1)$ & $192(0.2)$ & $224(0.4)$ \\
\hline
\end{tabular}

*All cancers other than cancers of the lung, breast, prostate, stomach, and intestine (small intestine, colon, and rectum).

†Percent annual change is based on the average annual change for the period 1969-1986 expressed as a percentage of the 1986 rate.

$\ddagger$ Age-adjusted rate based on 1986 U.S. population. 
Table 6. U.S. cancer incidence rates per 100000 population (SEER) for 1986 with yearly percent change based on 1973 through $1986^{*}$

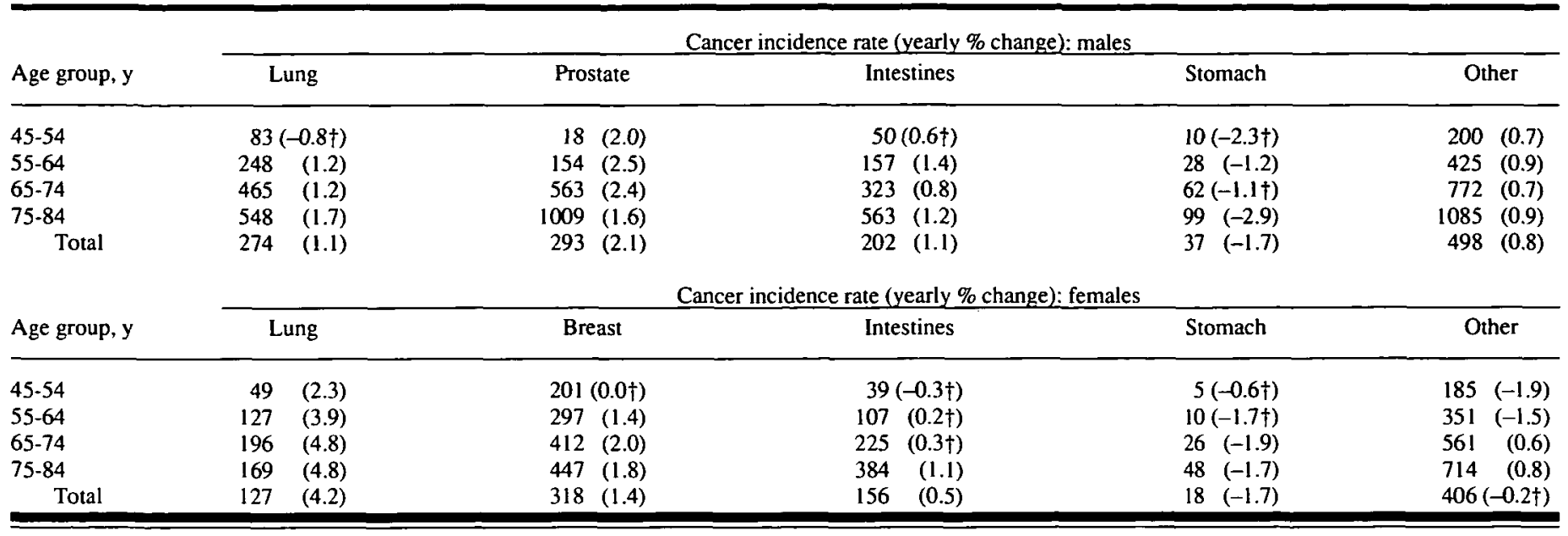

*Percent annual change is based on the average annual change for the period 1973-1986 expressed as a percentage of the 1986 rate.

$\dagger$ The trend is not significantly different from zero $(P<.01)$.

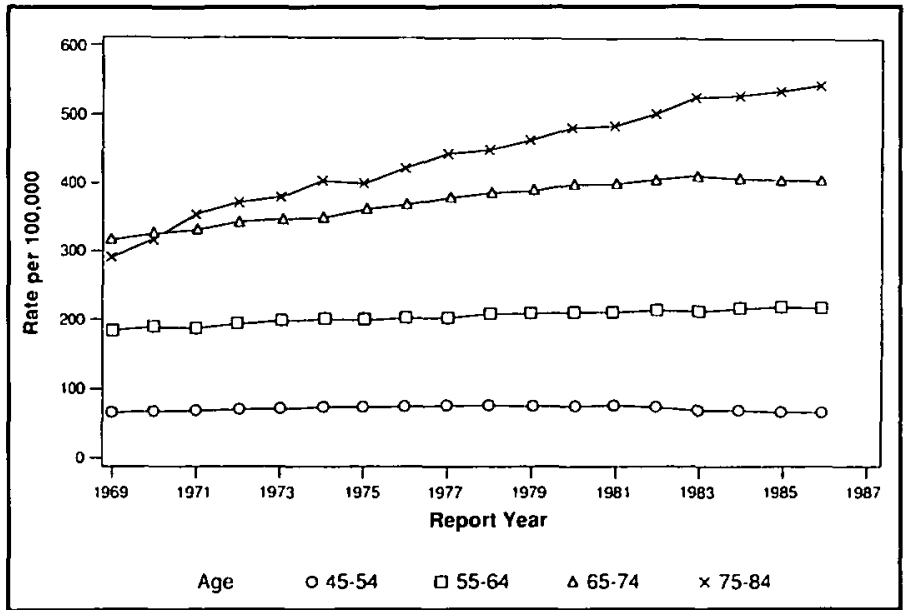

Fig. 7. Lung cancer (International Classification of Disease No. 162) agespecific death rates for males in the United States.

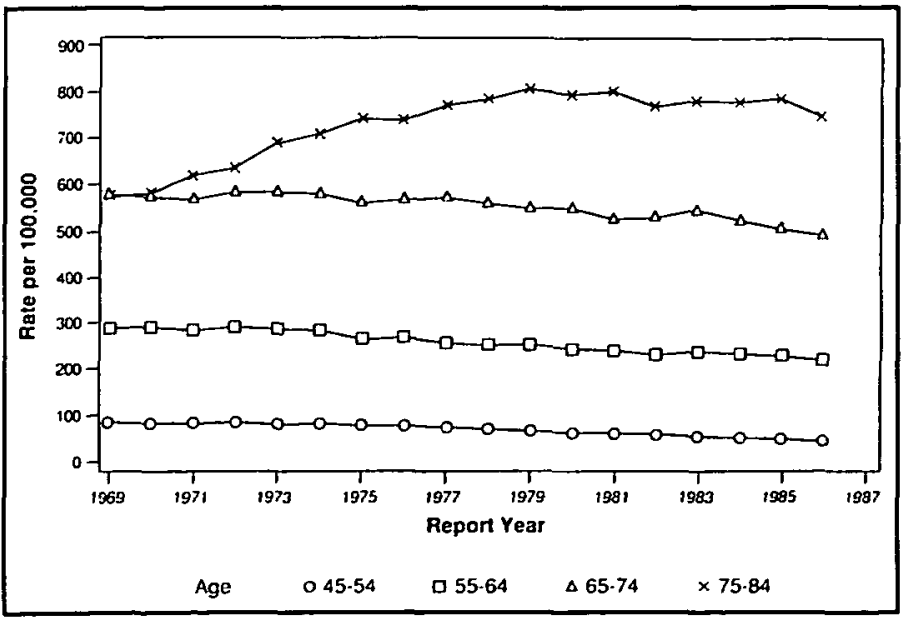

Fig. 8. Lung cancer (International Classification of Disease No. 162) agespecific death rates for males in England and Wales.

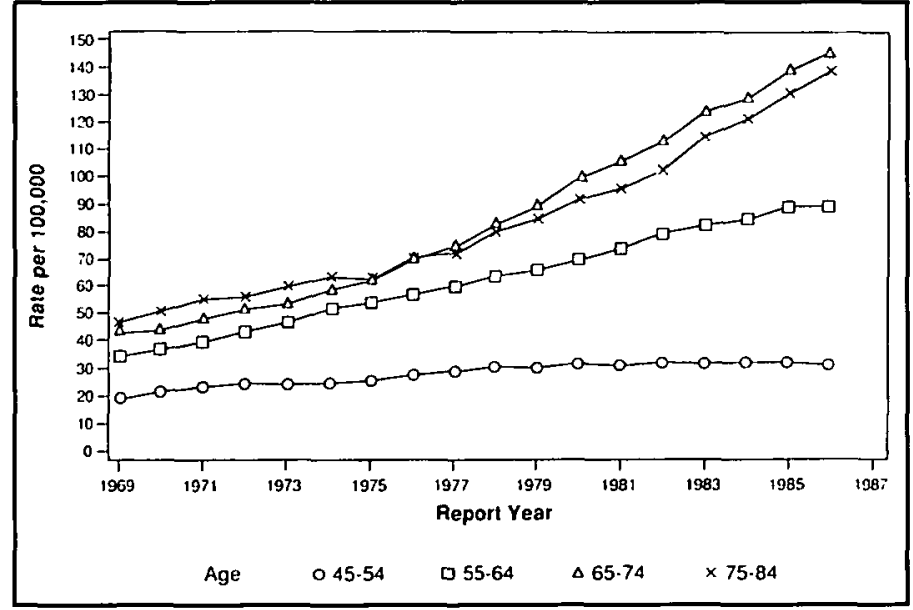

Fig. 9. Lung cancer (International Classification of Disease No. 162) agespecific death rates for females in the United States.

industrialized world that are not likely to be explained solely by alterations in cigarette smoking patterns. The other causes of changes in cancer incidence and mortality rates need to be determined. The trends of increasing and decreasing incidence and mortality rates reported here have implications for health care planning and may also suggest opportunities for research in cancer prevention.

\section{References}

(I) LOPEZ AD: Competing causes of death. A review of recent trends in mortality in industrialized countries with special reference to cancer. Ann N Y Acad Sci 609:58-76, 1990

(2) MUIR CS: Epidemiology, basic science, and the prevention of cancer: Implications for the future. Cancer Res 50:6441-6448, 1990

(3) Surveillance Program, Division of Cancer Prevention and Control, National CaNCER INSTitute: Cancer Statistics Review, 1973-1987. DHHS Publ No. (NIH) 90-2789. Bethesda, Md: NCI, 1990 
(4) Surveillance Program, Division of Cancer Prevention and Control, NATIONAL CanCER INSTITUTE: Cancer Statistics Review, 1973-1988. DHHS Publ No. (NIH)91-2789. Bethesda, Md: NCI, 1991

(5) DAvis DL, HoEl D, Fox J, ET AL: International trends in cancer mortality in France, West Germany, Italy, Japan, England and Wales, and the USA. Lancet 336:474-481, 1990

(6) DAvIS DL, HoEl D, Fox J, ET AL: International trends in cancer mortality in France, West Germany, Italy, Japan, England and Wales, and the United States. Ann N Y Acad Sci 609:5-48, 1990

(7) BAlLAR JC III: Death from all cancers. Trends in sixteen countries. Ann N Y Acad Sci 609:49-57, 1990

(8) Doll R, PETo R: The causes of cancer: Quantitative estimates of avoidable risks of cancer in the United States today. JNCI 66:1 191-1308, 1981

(9) BLyTH F, BeRAL V: Monitoring cancer trends. Br J Cancer 63:479-480, 1991

(IO) Stanley K, StJernswärd J, Koroltchouk V: Cancers of the stomach, lung and breast: Mortality trends and control strategies. World Health Stat Q 41:107-114, 1988

(II) HAENSZEL W: Epidemiological approaches to the study of cancer and other chronic diseases. Natl Cancer Inst Monogr 19:vii-xi, 1966

(12) National Research Council, Washington, D.C. Diet and Health. Implications for Reducing Chronic Disease Risk. Washington, DC: Natl Acad Press, 1989

(13) World Health Organization. Tobacco Alert, 4-7, 1991

(14) INTERNATIONAL AgENCY FOR RESEARCH ON CANCER: Tobacco Smoking. IARC Monogr Eval Carcinog Risk Hum 38:1-421, 1986

(I5) AXELSON O, DAVIS DL, FORESTIERE F, ET AL: Lung cancer not attributable to smoking. Ann N Y Acad Sci 609:165-178, 1990

(16) Mumford JL, ChapMan RS, Harris DB, ET al: Indoor air exposure to coal and wood combustion emissions associated with a high lung cancer rate in Xuan Wei, China. Environ Int 15:315-320, 1989

(J7) GeRbER GS, ChODAK GW: Routine screening for cancer of the prostate. J Natl Cancer Inst 83:329-335, 1991

(18) Koroltchouk V, Stanley K, STJERnSWÄrd J: The control of breast cancer. A World Health Organization Perspective. Cancer 65:2803-2810, 1990
(19) KOHLMEIER L, REHM J, HOFFMEISTER H: Lifestyle and trends in worldwide breast cancer rates. Ann N Y Acad Sci 609:259-268, 1990

(20) MILler AB: Epidemiological approaches to primary and secondary prevention of cancer. J Cancer Res Clin Oncol 117:177-185, 1991

(2I) PIKe MC, Krailo MD, Henderson BE, et al: "Hormonal" risk factors, "breast tissue age" and the age-incidence of breast cancer. Nature 303:767-770, 1983

(22) HaHN RA, MoOlgavkaR SH: Nulliparity, decade of first birth, and breast cancer in Connecticut cohorts, 1855 to 1945: An ecological study. Am J Public Health 79:1503-1507, 1989

(23) TRETL S, HALDORSEN T: A cohort analysis of breast cancer, uterine corpus cancer, and childbearing patterns in Norwegian women. J Epidemiol Community Health 44:215-219, 1990

(24) Blot WJ, Devesa SS, Fraumeni JF JR: Declining breast cancer mortality among young American women. JNCI 78:451-454, 1987

(25) Surveillance Program, Division of Cancer Prevention and Control, National Cancer InStITUTE: Cancer Statistics Review, 1973-1986, DHHS Publ No. (NIH)89-2789. Bethesda, Md: NCI, 1989

(26) Miller AB, Chamberlain J, Day NE, eT al: Report on a workshop of the UICC Project on Evaluation of Screening for Cancer. Int J Cancer 46:761769,1990

(27) Early Breast Cancer Trialists' Collaborative Group: Treatment of Early Breast Cancer. Worldwide Evidence 1985-1990, vol 1. New York: Oxford Univ Press, 1990

(28) HEADY JA, KENNAwAY EL: The increase in deaths attributed to cancer of the lung. Br J Cancer 3:311-320, 1949

(29) Stolley PD: When genius errs: R. A. Fisher and the lung cancer controversy. Am J Epidemiol 133:416-425, 1991

(30) Dol. R: Are we winning the fight against cancer? An epidemiological assessment. EARC-Muhlbock Memorial Lecture. Eur J Cancer 26:500508,1990

(3I) Dol L R: Progress against cancer: An epidemiologic assessment. The 1991 John C. Cassell Memorial Lecture. Am J Epidemiol 134:675-688, 1991

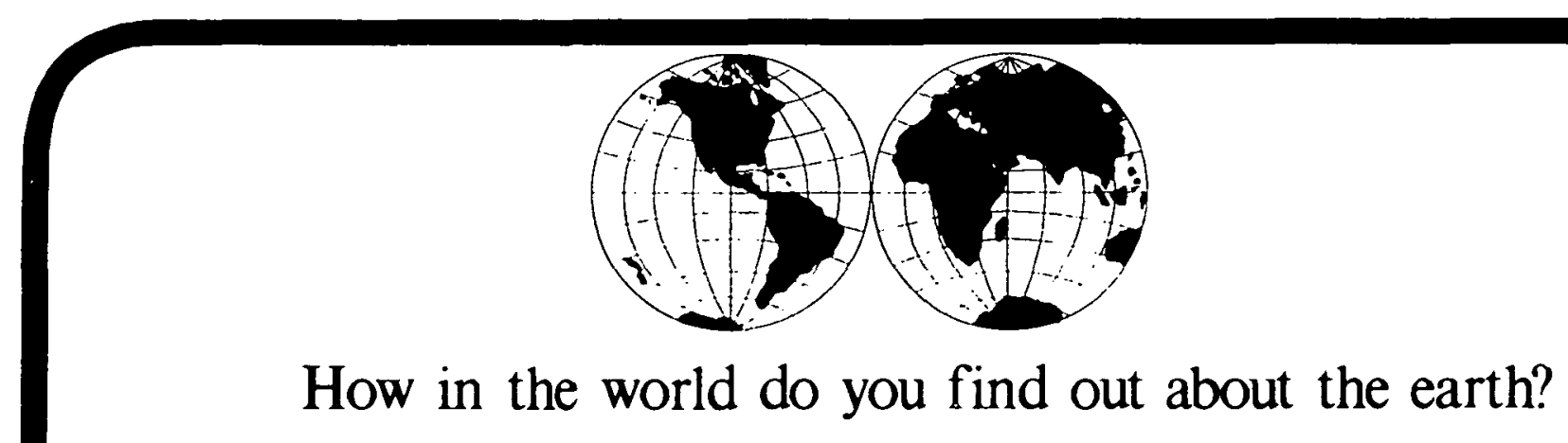

The Earth Science Data Directory (ESDD) is compiled and produced by the US Geological Survey, an agency of the Department of the Interior and the Federal Government's largest earth-science research agency.

References in the ESDD include information about:

- Data bases concerned with the geologic, hydrologic, cartographic, and biologic sciences - Data that supports the protection and management of

- Geographic, sociologic, economic, and demographic data sets

To secure information about becoming an ESDD user, write or call:

ESDD Project Manager

U.S. Geological Survey

801 National Center

Reston, Virginia 22092

(703) 648-7112 or FTS $959-7112$ 